
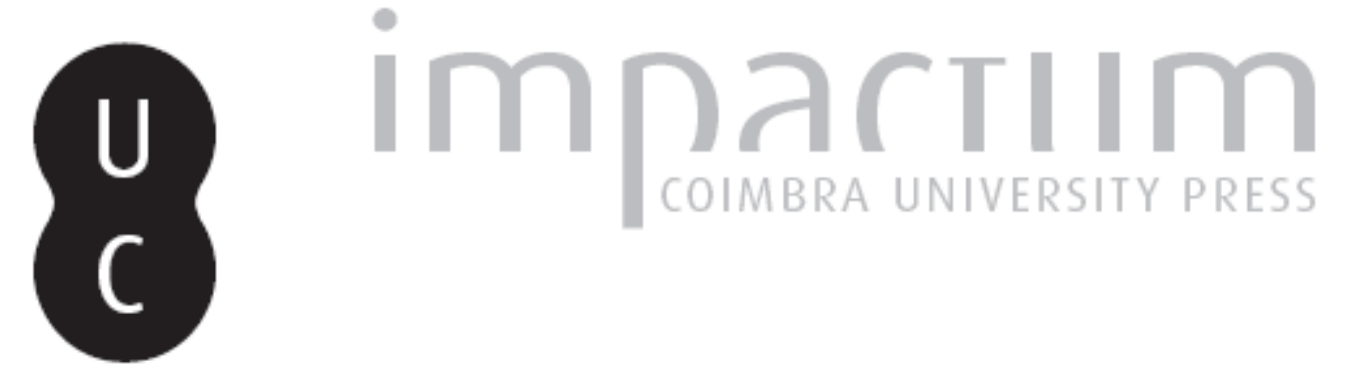

\title{
Cervídeo de bronze: inédito: (Oliveira de Frades)
}

Autor(es): Pereira, Sérgio; Medeiros, António

Publicado por: Imprensa da Universidade de Coimbra

URL persistente:

URl:http://hdl.handle.net/10316.2/45433

DOI:

DOI:https://dx.doi.org/10.14195/1647-8657_36_8

Accessed : $\quad$ 26-Apr-2023 13:10:55

A navegação consulta e descarregamento dos títulos inseridos nas Bibliotecas Digitais UC Digitalis, UC Pombalina e UC Impactum, pressupõem a aceitação plena e sem reservas dos Termos e Condições de Uso destas Bibliotecas Digitais, disponíveis em https://digitalis.uc.pt/pt-pt/termos.

Conforme exposto nos referidos Termos e Condições de Uso, o descarregamento de títulos de acesso restrito requer uma licença válida de autorização devendo o utilizador aceder ao(s) documento(s) a partir de um endereço de IP da instituição detentora da supramencionada licença.

Ao utilizador é apenas permitido o descarregamento para uso pessoal, pelo que o emprego do(s) título(s) descarregado(s) para outro fim, designadamente comercial, carece de autorização do respetivo autor ou editor da obra.

Na medida em que todas as obras da UC Digitalis se encontram protegidas pelo Código do Direito de Autor e Direitos Conexos e demais legislação aplicável, toda a cópia, parcial ou total, deste documento, nos casos em que é legalmente admitida, deverá conter ou fazer-se acompanhar por este aviso.

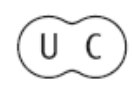


UNIVERSIDADE DE COIMBRA

FACULDADE DE LETRAS

\section{CONIMBRIGA}

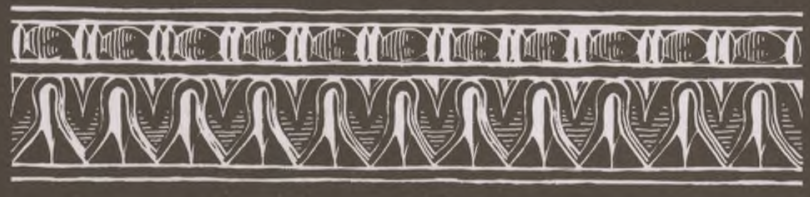

VOLUME XXXVI - 1997 
SÉRGIO PEREIRA

Licenciado em História - Variante de Arqueologia

ANTÓNIO MEDEIROS

Bolseiro de Investigação da Universidade de Faro

CERVÍDEO DE BRONZE, INÉDITO (OLIVEIRA DE FRADES)

“Conimbriga" XXXVI (1997) p. 161-164

Resumo: $\quad$ Apresenta-se a notícia de um achado, inédito, em Arcozelo das Maias (Oliveira de Frades). Refere-se a um veado de bronze, provavelmente de origem romana, relacionado com o culto a Diana, deusa da caça, e teria função de ex-voto. Tem a particularidade de ser o primeiro cervídeo romano registado em Portugal.

RÉsumé: $\quad$ Les auteurs présentent la découverte, inédite, à Arcozelo das Maias (Oliveira de Frades), d'un cerf en bronze, certainement d'origine romaine, en relation avec le culte de Diane, déesse de la chasse, ayant la fonction d'ex-voto. Il s'agit du premier exemplaire connu à ce jour au Portugal. 
(Página deixada propositadamente em branco) 


\section{CERVÍDEO DE BRONZE, INÉDITO (OLIVEIRA DE FRADES)}

Damos aqui breve notícia de um veado de bronze, a cujo proprietário, Sr. Aníbal Ferreira, agradecemos o ter-nos facultado a estatueta para estudo.

Foi achada no sítio de Lomba Gorda, no lugar de Borralhais, freguesia de Arcozelo das Maias, concelho de Oliveira de Frades. O Sr. Aníbal Ferreira, com o objectivo de aumentar o terreno de cultivo, revolveu o mesmo e foi então que encontrou a peça a uma profundidade de $50 \mathrm{~cm}$, juntamente com fragmentos de cerâmica, que não guardou por os considerar sem interesse. Hoje, à superfície, não se observam quaisquer vestígios arqueológicos. $\mathrm{O}$ achado poderá estar relacionado com uma estação romana localizada, a cerca de $3 \mathrm{Km}$, em Santa Cruz, também na mesma freguesia. Aqui encontrámos alguns fragmentos de tegulae e imbrices.

\section{Descrição:}

Comprimento: $72 \mathrm{~mm}$

Altura: $85 \mathrm{~mm}$

Espessura: $21 \mathrm{~mm}$

Peso: 146 gr

Pátina: Verde

Técnica: Cera perdida; fundição a cheio.

O cervídeo está em pé e apoiado nas quatro patas. Tem a cabeça erguida e o dorso direito. Relativamente às patas dianteiras, a esquerda encontra-se ligeiramente avançada em relação à direita; das traseiras, a esquerda está também mais avançada, mas o espaço entre ambas é maior. 
A haste esquerda tem quatro esgalhos, apresentando uma pequena fractura entre o primeiro e o segundo; a haste direita conserva apenas um esgalho completo, estando os restantes partidos.

Nota-se uma fractura na pata dianteira esquerda e algumas contusões: uma no pescoço e outra na ligação entre as duas hastes.

A pelagem está representada, em todo o corpo do cervídeo, por pequenas incisões.

Órgãos sexuais bem definidos.

\section{Comentários:}

1. Este bronze denota uma feitura cuidada, a nível global, embora, a nível do acabamento, o lado direito apresente melhor trabalho.

2. A pátina não é uniforme em toda a superfície: na zona do lombo foi removida por raspagem, segundo o proprietário para identificação do metal. Notam-se, ainda, sinais de oxidação nas zonas em que está fracturado ou onde houve contusão.

3. As figuras representando cervídeos são vulgares na Gália, onde existem algumas comparáveis, nomeadamente as que foram encontradas em Brèves - Nièvres e Autun-Champ des Orfèvres (Paul LEVEL et Stéphanie BOUCHER, Bronzes Figurés Antiques (Grecs, Étrusques et Romains), Musée Rolin, Ed. Ville d'AUTUN, 1975, pags. 89-90). Em Portugal, é o primeiro cervídeo romano a ser registado, segundo o Doutor Nunes Pinto, do Instituto de Arqueologia da Faculdade de Letras da Universidade de Coimbra; daí a sua importância.

4. A estatueta estará, certamente, relacionada com o culto a Diana, deusa da caça e dos bosques, e teria função de ex-voto. Outros animais, encontrados na Lusitânia e Hispânia, foram também eles relacionados com cultos à referida divindade.

5. Por se desconhecer o seu contexto arqueológico original, nada podemos adiantar acerca da eventual existência, nas imediações, de um santuário campestre dedicado à deusa da caça. 


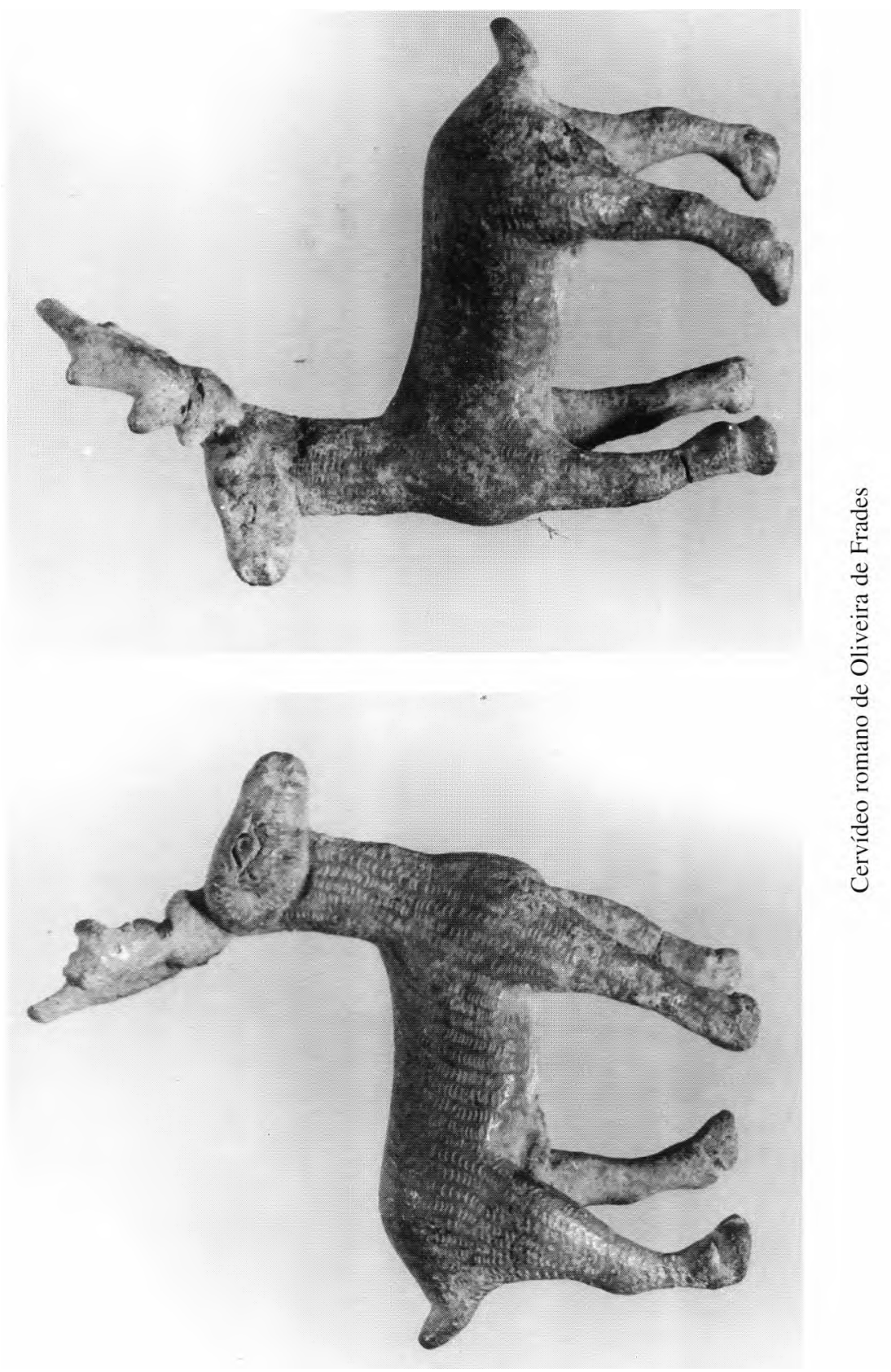

